\title{
Neurodegeneration in a Transgenic Mouse Model of Multiple System Atrophy Is Associated with Altered Expression of Oligodendroglial-Derived Neurotrophic Factors
}

\author{
Kiren Ubhi, ${ }^{1}$ Edward Rockenstein, ${ }^{1}$ Michael Mante, ${ }^{1}$ Chandra Inglis, ${ }^{1}$ Anthony Adame, ${ }^{1}$ Christina Patrick, ${ }^{1}$ \\ Kristen Whitney, ${ }^{1}$ and Eliezer Masliah ${ }^{1,2}$ \\ Departments of ${ }^{1}$ Neurosciences and ${ }^{2}$ Pathology, University of California, San Diego, School of Medicine, La Jolla, California 92093-0624
}

\begin{abstract}
Multiple system atrophy (MSA) is a neurodegenerative disorder characterized by striatonigral degeneration and olivo-pontocerebellar atrophy. Neuronal degeneration is accompanied by primarily oligodendrocytic accumulation of $\alpha$-synuclein ( $\alpha$ syn) as opposed to the neuronal inclusions more commonly found in other $\alpha$-synucleinopathies such as Parkinson's disease. It is unclear how $\alpha$ syn accumulation in oligodendrocytes may lead to the extensive neurodegeneration observed in MSA; we hypothesize that the altered expression of oligodendrocyte-derived neurotrophic factors by $\alpha$ syn may be involved. In this context, the expression of a number neurotrophic factors reportedly expressed by oligodendrocytes [glial-derived neurotrophic factor (GDNF), brain-derived neurotrophic factor (BDNF), and insulin-like growth factor 1 (IGF-1), as well as basic fibroblast growth factor 2 (bFGF2), reportedly astrocyte derived] were examined in transgenic mouse models expressing human $\alpha$ syn ( $h \alpha$ syn) under the control of either neuronal (PDGF $\beta$ or mThyl) or oligodendrocytic (MBP) promoters. Although protein levels of BDNF and IGF- 1 were altered in all the $\alpha$ syn transgenic mice regardless of promoter type, a specific decrease in GDNF protein expression was observed in the MBP-h $\alpha$ syn transgenic mice. Intracerebroventricular infusion of GDNF improved behavioral deficits and ameliorated neurodegenerative pathology in the MBP-h $\alpha$ syn transgenic mice. Consistent with the studies in the MBP-h $\alpha$ syn transgenic mice, analysis of GDNF expression levels in human MSA samples demonstrated a decrease in the white frontal cortex and to a lesser degree in the cerebellum compared with controls. These results suggest a mechanism in which $\alpha$ syn expression in oligodendrocytes impacts on the trophic support provided by these cells for neurons, perhaps contributing to neurodegeneration.
\end{abstract}

\section{Introduction}

Multiple system atrophy (MSA) is a sporadic, progressive, neurodegenerative disease that presents with motor abnormalities such as akinesia, rigidity, and postural instability, and is characterized neuropathologically by glial cytoplasmic inclusions (GCIs) of $\alpha$-synuclein ( $\alpha$ syn), primarily in oligodendrocytes (Arima et al., 1998; Tu et al., 1998; Wakabayashi et al., 1998a,b) unlike other $\alpha$-synucleinopathies, such as Parkinson's disease (PD) and dementia with Lewy bodies, which are characterized by neuronal aggregates of $\alpha$ syn. Despite the primarily oligodendrocytic accumulation of $\alpha$ syn, patients with MSA display considerable neuronal loss in the striatum, cerebellum, brainstem, and cortex, accompanied by astrogliosis, microgliosis, and myelin loss (Wakabayashi and Takahashi, 2006; Yoshida, 2007). Similar neurodegeneration has been observed in transgenic (Tg) mice overexpressing human $\alpha$ syn (h $\alpha$ syn) under the control of an oligodendrocytic-specific promoter [myelin basic protein (MBP)] (Shults et al., 2005); these Tg mice also develop oligodendrocytic accumulations of $\alpha$ syn.

Received Feb. 2, 2010; revised March 16, 2010; accepted March 23, 2010.

This work was supported by National Institutes of Health Grants AG 18440, NS 044233, AG 10435, and AG 022074 Correspondence should be addressed to Dr. Eliezer Masliah, Department of Neurosciences, University of California, San Diego, La Jolla, CA 92093-0624. E-mail: emasliah@ucsd.edu.

DOI:10.1523/JNEUROSCI.0567-10.2010

Copyright $\odot 2010$ the authors $\quad 0270-6474 / 10 / 306236-11 \$ 15.00 / 0$
Although a number of factors other than $\alpha$ syn accumulation, such as upregulated apoptotic mechanisms, activated microglia (Probst-Cousin et al., 1998), and mitochondrial dysfunction (Blin et al., 1994; Schulz and Beal, 1994), have been linked to cell death in MSA, it is the presence of $\alpha$ syn that has been most extensively investigated. However, it is as yet unclear how accumulation of oligodendrocytic $\alpha$ syn can lead to this extensive neurodegeneration. Oligodendrocytes have recently been reported to produce a number of neurotrophic factors (NTFs), including glial-derived neurotrophic factor (GDNF) (Du and Dreyfus, 2002; Wilkins et al., 2003), brain-derived neurotrophic factor (BDNF) (Dai et al., 2001, 2003), and insulin-like growth factor 1 (IGF-1) (Wilkins et al., 2001); therefore, it is possible that oligodendrocytic $\alpha$ syn accumulation, as seen in MSA may lead to alterations in the levels of these NTFs.

To investigate this hypothesis further, we sought to examine the expression of NTFs expressed by oligodendrocytes as well as the reportedly astrocyte-derived basic fibroblast growth factor 2 (bFGF2) (Ferrara et al., 1988), as a control, in Tg mice overexpressing human $\alpha$ syn (h $\alpha$ syn) under the control of either neuronal or oligodendrocytic promoters and in mice deficient for $\alpha$ syn ( $\alpha$ synKO). We were specifically interested in the NTFs that may be differentially expressed between $\mathrm{Tg}$ mice with h $\alpha$ syn under the oligodendrocytic promoter and those with h $\alpha$ syn under the control of neuronal promoters as we felt this would represent a class 
of NTF specifically affected by oligodendrocytic expression of $\alpha$ syn, as seen in MSA, rather than a more general response to $\alpha$ syn upregulation.

Although the levels of many NTFs examined were altered on $\alpha$-syn accumulation, only GDNF was specifically reduced in mice expressing $\alpha$-syn under an oligodendrocytic promoter. These results were confirmed in vitro, and GDNF infusion was demonstrated to ameliorate behavioral and neuropathological deficits in the MBP-h $\alpha$ syn Tg mice compared with saline-infused MBPh $\alpha$ syn Tg mice. Consistent with results from the MBP-h $\alpha$ syn $\mathrm{Tg}$ mice, we demonstrate a reduction in GDNF levels in the white matter of the frontal cortex and cerebellum of human MSA patients by ELISA and immunoblot. The results from this study suggest that $\alpha$ syn accumulation in oligodendrocytes may adversely impact their production of neurotrophic factors such as GDNF, which in turn may impair neuronal health and function, possibly resulting in neurodegeneration.

\section{Materials and Methods}

Generation of $\mathrm{Tg}$ mice. Mice expressing human $\alpha$ syn under the control of the MBP promoter (MBP-h $\alpha$ syn Tg) were generated as previously described (Shults et al., 2005); specifically, this study used the MBP1 line. The MBP-h $\alpha$ syn line 1 mice were chosen for this study as they expressed an intermediate level of $\alpha$ syn expression compared with the other lines; they were able to be assessed behaviorally and were breedable. In contrast, other higher expressing lines were less viable and aggressive, making them less suitable for this study. The MBP-h $\alpha$ syn line 1 mice have previously been shown to accumulate $\alpha$ syn in oligodendrocytes from 3 months of age and to display neuropathological alterations including myelin loss and astrogliosis and behavioral deficits (Shults et al., 2005). Comparisons in the levels of neurotrophic factors were made with mice expressing human $\alpha$ syn under the control of the neuronal promoters, platelet-derived growth factor- $\beta$ (PDGF $\beta$ ) or mThy1 (Rockenstein et al., 2002), and in mice deficient for $\alpha$ syn (stock number 003692; The Jackson Laboratory). Determination of mouse genotype was assessed via genomic DNA that was extracted from tail biopsies and analyzed by PCR amplification, as previously reported (Rockenstein et al., 1995). To investigate the age-related changes in neurotrophic factor expression, a total of 15 non-Tg (NTg) mice ( 6 months, $n=5$; 9 months, $n=5$; 12 months, $n=5)$ and 15 MBP-h $\alpha$ syn ( 6 months, $n=5$; 9 months, $n=5$; 12 months, $n=5$ ) were used.

GDNF infusions. To investigate the effect of GDNF infusion in mice expressing $h \alpha$ syn under an oligodendrocytic promoter, a total of 24 mice was used; they received $0.08 \mu \mathrm{g} / \mu \mathrm{l} \mathrm{GDNF}$ (Invitrogen) (MBP-h $\alpha$ syn Tg mice, $n=6$; NTg mice, $n=6$ ) or saline (MBP-h $\alpha$ syn Tg mice, $n=6$; NTg mice, $n=6$ ) delivered by intracerebroventricular osmotic minipump (Alzet; Charles River Laboratories) infusion at a rate of $0.25 \mu \mathrm{l} / \mathrm{h}$ for $14 \mathrm{~d}$. The minipump was implanted subcutaneously on the back under light anesthesia as previously described (Rose et al., 2009). All experiments were approved by the Animal Subjects Committee at the University of California, San Diego, and were performed according to National Institutes of Health (NIH) recommendations for animal use. Mice underwent behavioral testing in the 2 weeks after infusion and were killed at the end of this period. Mice used were 8 months of age and on a C57BL/6 background.

Pole test. For the pole test, animals were placed head upward on top of a vertical wooden pole $50 \mathrm{~cm}$ long and $1 \mathrm{~cm}$ in diameter. When placed on the pole, animals orient themselves downward and descend the length of the pole. Groups of mice received training that consisted of five trials for each session. For testing, animals received five trials and time taken to point downward (T-turn) and total time to descend (T-total) were measured.

Buried pellet. To assess olfactory behavior, mice were placed in a cage in which a food pellet had been hidden under the bedding of the cage at one end. Mice completed five trials with the time taken for the mice to find the pellet being recorded each time. Before the buried pellet test, mice underwent a taste preference test in which they were presented with a number of food pellet options of varying taste and smell- the pellet
Table 1. Demographic characteristics of human samples

\begin{tabular}{llll}
\hline Group & Age $($ mean \pm SEM) & Gender (male/female) & PMI (mean \pm SEM) \\
\hline Control $(n=3)$ & $74.3 \pm 4.4$ & $2 / 1$ & $32.7 \pm 2.7$ \\
MSA $(n=3)$ & $65.0 \pm 4.6$ & $3 / 0$ & $17.3 \pm 2.9$ \\
\hline
\end{tabular}

PMI, Postmortem interval.

chosen by the mouse most consistently of five trials was the pellet hidden in the buried pellet test.

Tissue processing. Following NIH guidelines for the humane treatment of animals, under anesthesia mice were killed and brains were removed. The right hemibrain was immersion-fixed in $4 \%$ paraformaldehyde in PBS, pH 7.4, and serially sectioned at $40 \mu \mathrm{m}$ with the Vibratome (Leica) for subsequent analysis of neurodegeneration. The left hemibrain was kept at $-80^{\circ} \mathrm{C}$ for biochemical analysis.

Oligodendroglial differentiation of neuronal precursor cells and lentivirus- $\alpha$ syn infection. To investigate the effects of $\alpha$ syn on oligodendrocytes in vitro, neuronal precursor cells (NPCs) derived from adult rat hippocampus were differentiated into oligodendrocytes and infected with lentivirus (LV)- $\alpha$ syn. Adult rat hippocampal NPCs were cultured routinely for expansion essentially as previously described (Hsieh et al., 2004; Ray and Gage, 2006). Briefly, cells were grown as monolayers on poly-ornithine/laminin-coated plates in NPC basal media (DMEM/F$12,1 \% \mathrm{~N} 2$ supplement, $2 \mathrm{~mm}$ L-glutamine, and $1 \%$ penicillin-streptomycin) supplemented with $20 \mathrm{ng} / \mathrm{ml} \mathrm{FGF2} \mathrm{(fibroblast} \mathrm{growth} \mathrm{factor} \mathrm{2)}$ (NPC expansion media). For differentiation into oligodendrocytes, cells were plated onto poly-ornithine/laminin-coated plates or coverslips in NPC expansion media, and transferred the following day (day 0 ) to NPC oligodendrocyte differentiation media (NPC basal media supplemented with $500 \mathrm{ng} / \mathrm{ml} \mathrm{IGF-1).} \mathrm{Cells} \mathrm{were} \mathrm{allowed} \mathrm{to} \mathrm{differentiate} \mathrm{for} 4 \mathrm{~d}$ without additional feeding and were infected with LV- $\alpha$ syn, or empty vector as a control (LV-control), and left for an additional $3 \mathrm{~d}$. After differentiation and infection, cells were lysed in TNE [20 mM Tris- $\mathrm{HCl}, 150 \mathrm{~mm} \mathrm{NaCl}, 1$ mм EDTA, 1\% NP-40, 5 mм 2-mercaptoethanol, $1 \times$ protease inhibitor mixture (Calbiochem) and $1 \times$ phosphatase inhibitor mixture (Calbiochem) containing sodium orthovanadate] with $1 \%$ Triton X-100 for immunoblot analysis or fixed in $4 \%$ paraformaldehyde for immunocytochemistry. Conditioned media was collected from each condition, and GDNF levels in this media were assessed via ELISA. $\mathrm{KCl}(55 \mathrm{~mm})$ was used to enhance GDNF secretion as a positive control, as previously described (Oh-hashi et al., 2009).

Immunohistochemistry and stereological analysis. To investigate the effects of GDNF in MBP-h $\alpha$ syn Tg mice, $40 \mu \mathrm{m}$ vibratome sections were immunolabeled overnight with antibodies against GDNF (1:250; Santa Cruz), the dendritic marker microtubule-associated protein 2 (MAP-2) (1:1000; mouse monoclonal; Millipore Bioscience Research Reagents), the neuronal marker NeuN (1:1000; Millipore Bioscience Research Reagents), and the astroglial marker glial fibrillary acidic protein (GFAP), the dopaminergic marker tyrosine hydroxylase (TH) (1:200; Millipore Bioscience Research Reagents), dopamine transporter (DAT) (1:200; Millipore Bioscience Research Reagents), and $\alpha$ syn (1:1000; Millipore Bioscience Research Reagents) followed by incubation with speciesappropriate secondary antibodies (1:2000; Vector Laboratories). Sections were transferred to SuperFrost slides (Thermo Fisher Scientific) and mounted under glass coverslips with antifading media (Vector Laboratories). The immunolabeled blind-coded sections were analyzed with the laser-scanning confocal microscope (MRC1024; Bio-Rad).

Stereological analysis of the numbers of $\mathrm{TH}$ - and $\mathrm{NeuN}$-immunoreactive cells, in the substantia nigra and frontoparietal cortex, respectively, was conducted with Stereo Investigator software (MBF Biosciences); images were collected according to the optical dissector method and expressed as cells per unit volume. TH and DAT immunoreactivity levels in the caudate-putamen were assessed by obtaining optical density measurements using the $\mathrm{NIH}$ ImageQuant 1.43 program and corrected against background levels; this is presented as "corrected optical density," where the background signal has been subtracted from the optical density measurements.

Immunoblot analysis. Protein levels of NTF, GDNF family members, GDNF receptors, and total and phosphorylated $\alpha$ syn (S129) were determined by immunoblot analysis in brain tissue [frozen posterior hemi- 


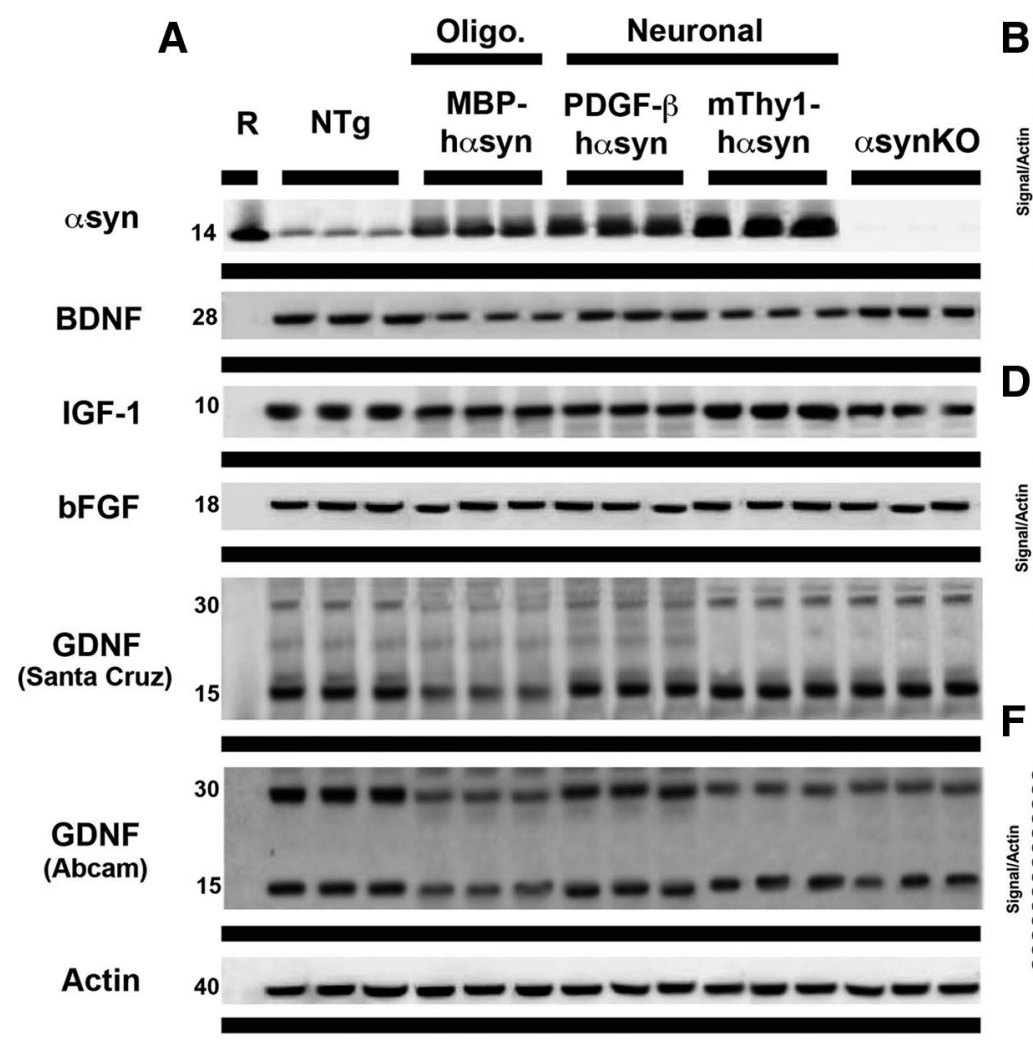

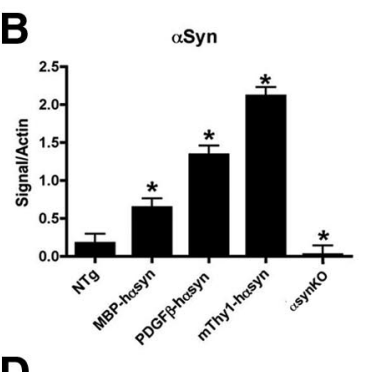
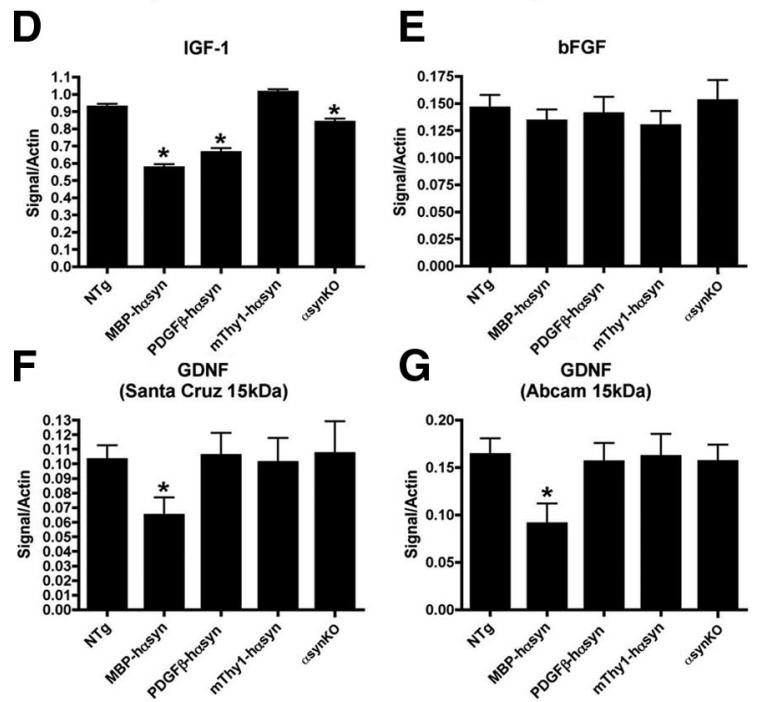

Figure 1. Altered expression of neurotrophic factors on $\alpha$ syn overexpression in Tg mouse models of $\alpha$-synucleinopathy. To examine the effect of $\alpha$ syn on expression levels of neurotrophic factors, immunoblot analysis ( $\boldsymbol{A}$ ) was conducted on mouse brain homogenates from the posterior hemibrain, to detect the levels of $\alpha$ syn, BDNF, IGF-1, bFGF, and GDNF in Tg mouse models expression $\alpha$ syn under oligodendrocytic (MBP-h $\alpha$ syn, $n=5$; age, 8 months) or neuronal (PDGF- $\beta$-h $\alpha$ syn, $n=5$; age, 8 months; mThy1-h $\alpha$ syn, $n=5$; age, 8 months) promoters and $\alpha$ synK0 mice; representative blots from $n=3$ of each group are shown. Quantitative analysis $(\boldsymbol{B}-\boldsymbol{G})$ of the levels of $\alpha$ syn, BDNF, IGF-1, bFGF, and GDNF, respectively, is also presented. *Significant difference between NTg mice and the various $\alpha$ syn $\mathrm{Tg}$ lines ( $p<0.05$, one-way ANOVA and post hoc Fisher). Error bars indicate SEM.

brain, processed to obtain the cytosolic fraction, as previously described (Shults et al., 2005)] from the MBP-h $\alpha$ syn ( $n=5$; age, 8 months), PDGF $\beta$-h $\alpha$ syn ( $n=5$; age, 8 months), and mThyl-h $\alpha$ syn ( $n=5$; age, 8 months) Tg and NTg ( $n=5$; age, 8 months) mice or cell lysates from oligodendrocytes derived from neuronal precursor cells.

Twenty micrograms of total protein per mouse were loaded onto $4-12 \%$ Bis-Tris (Invitrogen) SDS-PAGE gels and transferred onto Immobilon membranes, incubated with two antibodies against GDNF (1: 1000; Santa Cruz; and 1:1000; Abcam), BDNF (1:1000; Millipore), IGF-1 (1:1000; Abcam), bFGF2 (1:1000; Sigma-Aldrich), Neurturin (1:1000; Millipore), Artemin (1:1000; Abbiotec), RET receptor (1:1000; Abcam), c-RET receptor (1:1000; Millipore Bioscience Research Reagents), GFR $\alpha 3$ receptor (1:1000; Millipore Bioscience Research Reagents), GFR $\alpha 1$ (1:1000; Abcam), phospho- $\alpha$ syn (11A5; 1:1000) (Fujiwara et al., 2002), and total $\alpha$ syn (1:1000; Millipore Bioscience Research Reagents). After overnight incubation with primary antibodies, membranes were incubated in appropriate secondary antibodies, reacted with ECL, and developed on a VersaDoc gel-imaging machine (Bio-Rad). Anti- $\beta$-actin (1:1000; Sigma-Aldrich) antibody was used to confirm equal loading.

RNA extraction and quantification of $m R N A$ by quantitative real-time PCR analysis. Total RNA was extracted from MBP-h $\alpha$ syn Tg mice and NTg mice; three independent sets of RNA were isolated for each mouse using the RNeasy kit (QIAGEN) per the manufacturer's instructions. All the samples were treated with DNase I to eliminate genomic DNA contamination. RNA quantification was determined by spectrophotometer readings. The ratio of $\mathrm{OD}_{260} / \mathrm{OD}_{280}$ was used to evaluate the purity of the nucleic acid samples, and the quality of the extracted total RNA was determined using agarose gel electrophoresis.

For cDNA synthesis, $1 \mu \mathrm{g}$ of total RNA was reverse transcribed using iScript cDNA Synthesis kit (Bio-Rad). Quantitative real-time PCR (qRTPCR) experiments were performed using the iQ5 Detection System (Bio-
Rad). Amplification was performed on a cDNA amount equivalent to 25 ng of total RNA with $1 \times$ iQ SYBRGreen Supermix (Bio-Rad) containing dNTPs, $\mathrm{MgCl}_{2}$, TaqDNA polymerase, and forward and reverse primers. PCRs were performed on three independent sets of template. Experimental samples and no-template controls were all run in duplicate. The PCR cycling parameters were as follows: $50^{\circ} \mathrm{C}$ for $2 \mathrm{~min}, 95^{\circ} \mathrm{C}$ for $10 \mathrm{~min}$, and 40 cycles of $94^{\circ} \mathrm{C}$ for $15 \mathrm{~s}, 60^{\circ} \mathrm{C}$ for $1 \mathrm{~min}$. Finally, a dissociation protocol was also performed at the end of each run to verify the presence of a single product with the appropriate melting point temperature for each amplicon. The amount of studied cDNA in each sample was calculated by the comparative threshold cycle method and expressed using mouse actin as an internal control.

In situ hybridization. An antisense probe was generated against mouse GDNF with the following sequence: $5^{\prime}-3^{\prime}$, ccaaggaggaactgatctttcgatattgcagcggttcctgtgaatcggcc, as previously described (Nosrat et al., 1996), with nucleotide substitutions for the mouse sequence. The probe was labeled with digitoxin using the DIG Oligonucleotide Tailing kit (Roche) per the manufacturer's instructions. Paraffin sections were prepared for in situ by deparaffinization through xylene and graded ethanol from 100 to $50 \%$, incubated in DEPC-PBS for $5 \mathrm{~min}$, and then fixed in DEPC- $4 \%$ paraformaldehyde-PBS. After acetylation with fresh $0.1 \mathrm{~m} \mathrm{TEA}$ (triethanolamine) buffer and acetic anhydride to $0.5 \%(\mathrm{v} / \mathrm{v})$, slides were washed in $2 \times$ SSC. Slides were prehybridized at $52^{\circ} \mathrm{C}$ with DIG Easy Hyb solution (Roche) for $30 \mathrm{~min}$ and then hybridized for an additional $4 \mathrm{~h}$ with DIG Easy Hyb solution (Roche) plus the DIG-labeled GDNF probe (1: $500)$. After hybridization, slides went through posthybridization washes with $2 \times$ SSC and $0.1 \% \times$ SDS. Slides were then dehydrated and coverslipped. Multiple slides were prepared for double labeling with cell typespecific antibodies. Slides hybridized with the sense probe were clear.

Determination of GDNF protein content by ELISA. The concentration of GDNF protein in mouse whole-brain homogenate tissue was deter- 


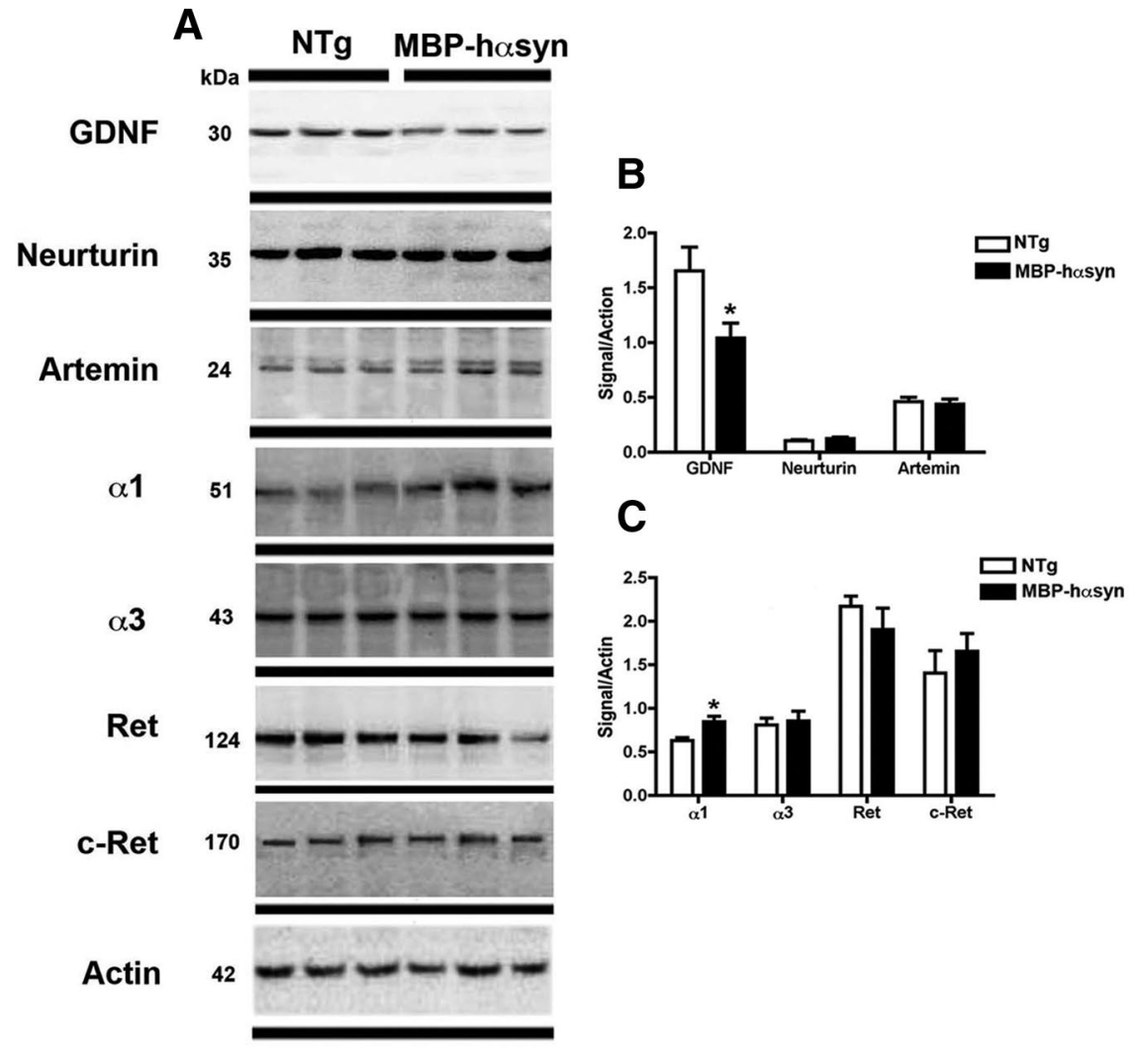

Figure 2. Characterization of GDNF family members and receptors in MBP-h $\alpha$ syn Tg mice. To examine the specificity of the $\alpha$ syn effect on GDNF, immunoblot analysis ( $\boldsymbol{A}$ ) of GDNF-family members (Neurturin and Artemin) and GDNF receptors in MBPh $\alpha$ syn Tg mice ( $n=5$; age, 8 months) and NTG mice ( $n=5$; age, 8 months) was conducted on mouse brain homogenates from the posterior hemibrain; representative blots from $n=3$ of each group are shown. Quantitative analysis of expression levels of Neurturin and Artemin $(\boldsymbol{B})$ and of GDNF receptors $(\boldsymbol{C})$ in MBP-h $\alpha$ syn Tg mice is also presented. *Significant difference between MBP-h $\alpha$ syn Tg and NTg mice ( $p<0.05$, one-way ANOVA and post hoc Fisher). Error bars indicate SEM.

mined by ELISA; briefly, the samples were sonicated in a homogenization buffer (20 mm Tris, pH 8, $137 \mathrm{~mm} \mathrm{NaCl}, 1 \%$ Nonidet P-40, $1.7 \mu \mathrm{g} / \mathrm{ml}$ phenylmethylsulfonyl fluoride, $10 \mu \mathrm{g} / \mathrm{ml}$ aprotinin, $1 \mu \mathrm{g} / \mathrm{ml}$ leupeptin, and $0.5 \mathrm{~mm}$ sodium vanadate) at a tissue concentration of $30 \mu \mathrm{l} / \mathrm{mg}$. Tissue levels of GDNF was determined in homogenates by ELISA according to the supplier's protocol (Promega). A similar method was used to determine GDNF levels in the conditioned media from NPC-derived oligodendrocytes infected with LV- $\alpha$ syn and in the human control and MSA brain samples.

Humans samples. Control and MSA human brain samples from the white matter of the frontal cortex and cerebellum were obtained from the Alzheimer's Disease Research Center (University of California, San Diego) (Table 1). Brain samples were homogenized in buffer containing $1.0 \mathrm{~mm}$ HEPES, $5.0 \mathrm{~mm}$ benzamidine, $2.0 \mathrm{~mm}$ 2-mercaptoethanol, $3.0 \mathrm{~mm}$ EDTA, $0.5 \mathrm{~mm}$ magnesium sulfate, $0.05 \%$ sodium azide, $\mathrm{pH}$ to 8.8 , and centrifuged at $100 \mathrm{k}$ for $1 \mathrm{~h}$ (Ultracentrifuge; Beckman Coulter) to obtain cytosolic (soluble) and particulate (insoluble, membrane-bound) fractions. The cytosolic fraction was used for immunoblot analysis as described above.

Statistical methods. Differences between groups were tested using one- and two-factor ANOVA with Fisher's PLSD post hoc tests. Additional preliminary analysis between control and infused groups was conducted using the unpaired, two-tailed, Student's $t$ test. All results are expressed as mean \pm SEM.

\section{Results}

Alterations in levels of NTFs in transgenic mice overexpressing $\alpha$ syn and $\alpha$ synKO mice

To assess the expression levels of NTFs in transgenic mice expressing $\alpha$ syn under neuronal promoter, oligodendrocytic promoters or $\alpha$ synKO mice immunoblot analysis was conducted (Fig. 1A). The levels of BDNF protein were reduced in all the lines examined, including the $\alpha$ synKO mice, compared with NTg mice (Fig. $1 A, C$ ), whereas IGF-1 was reduced in the MBPh $\alpha$ syn Tg mice, the PDGF- $\beta$ h $\alpha$ syn Tg mice, and the $\alpha$ synKO mice but not the mThy-1-h $\alpha$ syn Tg mice, compared with NTg mice (Fig. 1 $A, D$ ); bFGF appeared unchanged across the Tg lines compared with NTg mice (Fig. $1 A, E$ ).

The only NTF that was differentially reduced specifically in the MBP-h $\alpha$ syn $\mathrm{Tg}$ mice was GDNF. GDNF was identified as a $15 \mathrm{kDa}$ band (corresponding to the monomer) and a $30 \mathrm{kDa}$ band (corresponding to the homodimer) in the cytosolic fractions of the NTg and various lines of hosyn Tg mice. Levels of GDNF monomer were reduced by $57 \%$, with a similar reduction seen in the dimer in the MBP-h $\alpha$ syn Tg mice when compared with NTg; this was confirmed by the use of two separate GDNF antibodies (Fig. 1A; analyzed in $F$ and $G$ ).

Levels of NTFs have been reported to decrease with age (Rudman et al., 1981; Shibasaki et al., 1984; Iranmanesh et al., 1991; Hayashi et al., 2001; Mattson et al., 2004; Tapia-Arancibia et al., 2008; Aleman and Torres-Aleman, 2009); therefore, to investigate the impact of age on the levels of GDNF and other NTFs, immunoblot analysis of levels of GDNF, BDNF, IGF-1, and bFGF was conducted (supplemental Fig. 1, available at www.jneurosci.org as supplemental material). A decrease in BDNF levels was observed with increasing age, from 6,9 , to 12 months of age, in both the NTg and MBP-h $\alpha$ syn mice, consistent with previous reports (Hayashi et al., 2001), MBP-h $\alpha$ syn mice displayed reduced BDNF expression levels compared with the agematched NTg mice at each of the three ages examined (supplemental Fig. 1, available at www.jneurosci.org as supplemental material). Levels of GDNF remained stable from 6 to 12 months in the NTg mice; the MBP-h $\alpha$ syn mice, however, displayed markedly reduced GDNF expression levels compared with the age-matched Ntg mice at each of the three ages examined (supplemental Fig. 1, available at www.jneurosci.org as supplemental material).

To determine whether levels of other GDNF family members such as Neurturin and Artemin were altered, immunoblot analysis was conduced and showed that levels of these NTFs were similar among NTg and MBP-h $\alpha$ syn Tg mice (Fig. $2 A$; analyzed in $B$ ). In contrast, immunoblot analysis of levels of GDNF family receptors demonstrated an increase in the protein levels of the GFR $\alpha 1$ receptor in the MBP-h $\alpha$ syn Tg mice compared with NTg mice (Fig. 2; analyzed in $C$ ). Consistent with immunoblot studies, ELISA analysis of GDNF protein levels in whole-brain homogenates showed a $60 \%$ reduction in GDNF levels in the MBP-h $\alpha$ syn Tg mice (1315 \pm $104.3 \mathrm{pg} / \mathrm{ml})$ compared with NTg mice $(3333 \pm 103.9 \mathrm{pg} / \mathrm{ml})$.

\section{Characterization of GDNF mRNA expression in MBP-h $\alpha$ syn Tg mice}

To investigate cell type-specific mRNA expression in the MBPh $\alpha$ syn Tg mice and NTg mice, we conducted in situ hybridization (ISH) and observed GDNF mRNA expression in oligodendro- 
cytes using colabeling with oligodendrocytic markers MBP (Fig. $3 A, B$ ), galactocerebroside (GalC) (Fig. $3 C, D$ ), and in astrocytes by colabeling with GFAP (Fig. $3 E, F$ ) in both the MBPhosyn Tg mice and NTg mice. Analysis showed a similar percentage of GDNFpositive astrocytes and oligodendrocytes in both the MBP-h $\alpha$ syn Tg mice and NTg mice, with in each case three times more astrocytes expressing GDNF mRNA than oligodendrocytes (Fig. 3I). Consistent with the ISH, qRT-PCR showed no difference in the levels of GDNF mRNA between the MBP-h $\alpha$ syn Tg mice and NTg mice.

\section{In vitro $\alpha$ syn accumulation in} oligodendroglial cells results in reduced expression of GDNF

To further examine the relationship between oligodendrocytic $\alpha$ syn expression and GDNF levels, oligodendrocytes derived from neuronal precursor cells were infected with LV- $\alpha$ syn and examined for levels of GDNF by immunocytochemistry (Fig. $4 A-F$ ) or immunoblot analysis (Fig. $4 G$ ).

Differentiation to an oligodendrocytic phenotype was demonstrated by immunoreactivity for the oligodendrocytic marker MBP (Fig. 4A,B) and immunoblot analysis with oligodendrocytic (GalC), astrocytic (GFAP), and neuronal (Tuj1) antibodies (Fig. 4G). Cells infected with LV- $\alpha$ syn displayed higher levels of $\alpha$ syn immunoreactivity compared with those infected with LV-control (Fig. 4C,D), and GDNF immunoreactivity was markedly reduced in oligodendrocytes infected with LV- $\alpha$ syn compared with LV-control (Fig. 4E, F). Consistent with the immunohistochemistry, immunoblot analysis demonstrated a reduced expression of GDNF in cells infected with LV$\alpha$ syn, as confirmed by two different GDNF antibodies (Fig. $4 G$ ). To examine the levels of GDNF secreted by the cells under the different conditions, media from each group were taken and analyzed by ELISA (Fig. 4H). Consistent with the immunocytochemistry and immunoblot results, media from cells infected with LV- $\alpha$ syn expressed less GDNF than that from uninfected cells. Application of $\mathrm{KCl}(55 \mathrm{~mm})$ into the cell culture, an enhancer of GDNF secretion (Oh-hashi et al., 2009), was able to increase GDNF secretion in the uninfected cells by $30 \%$ but had a minimal/no effect on the levels of GDNF secreted into the media by the LV- $\alpha$ syn-infected cells (Fig. $4 H$ ). These results imply that, in the uninfected cells, there may be some GDNF "reserve" that is able to be released on $\mathrm{KCl}$ administration; however, the LV- $\alpha$ syn-infected cells lack this reserve and are unable to increase secretion on $\mathrm{KCl}$ administration, perhaps because of the overall decreased expression of GDNF in these cells.

Together, the results from the MBP-h $\alpha$ syn Tg mice and the NPC-derived oligodendrocytes suggest that overexpression of $\alpha$ syn affects the expression levels of GDNF, which may in turn also alter its secretion characteristics.

\section{GDNF infusion attenuates behavioral deficits in the MBP-hasyn Tg mice}

Although a number of NTFs were disturbed in the MBP-h $\alpha$ syn $\mathrm{Tg}$ mice, we chose to focus on GDNF as it was the only NTF that appeared to be specifically altered in the MBP-h $\alpha$ syn $\mathrm{Tg}$ mice. Having established that the levels of GDNF were reduced in the MBP-h $\alpha$ syn Tg, we sought to investigate whether GDNF infusion might revert the behavioral and neurodegenerative alterations observed in the MBP-h $\alpha$ syn Tg mice. For this purpose, mice received $0.08 \mu \mathrm{g} / \mu \mathrm{l}$ GDNF delivered by osmotic pump infusion over a period of $14 \mathrm{~d}$ and underwent behavioral testing in the 2 weeks after infusion.

Pole test analysis, designed to investigate motor behavior (Matsuura et al., 1997), showed a significant increase in Ttotal and T-turn times in the saline-infused MBP-h $\alpha$ syn $\mathrm{Tg}$ mice compared with saline-infused NTg controls (Fig. $5 A, B$ ) as has been previously reported (Shults et al., 2005; Ubhi et al., 2009). GDNF infusion significantly decreased T-total and T-turn times in the MBP-h $\alpha$ syn Tg mice compared with the saline-infused MBPh $\alpha$ syn Tg mice (Fig. $5 A, B$ ). GDNF infusion had no effect on the T-total and T-turn times of NTg mice.

In the buried pellet test, designed to assess olfactory behavior, saline-infused MBP-h $\alpha$ syn Tg mice took significantly longer to find the buried food pellet than the saline-infused NTg control mice, indicating an olfactory deficit in these animals (Fig. 5C). GDNF infusion significantly lowered the time taken by the MBP-hosyn Tg mice to find the pellet compared with saline-infused MBP-h $\alpha$ syn mice, bringing their time closer to saline-infused NTg control mice (Fig. 5C). GDNF 


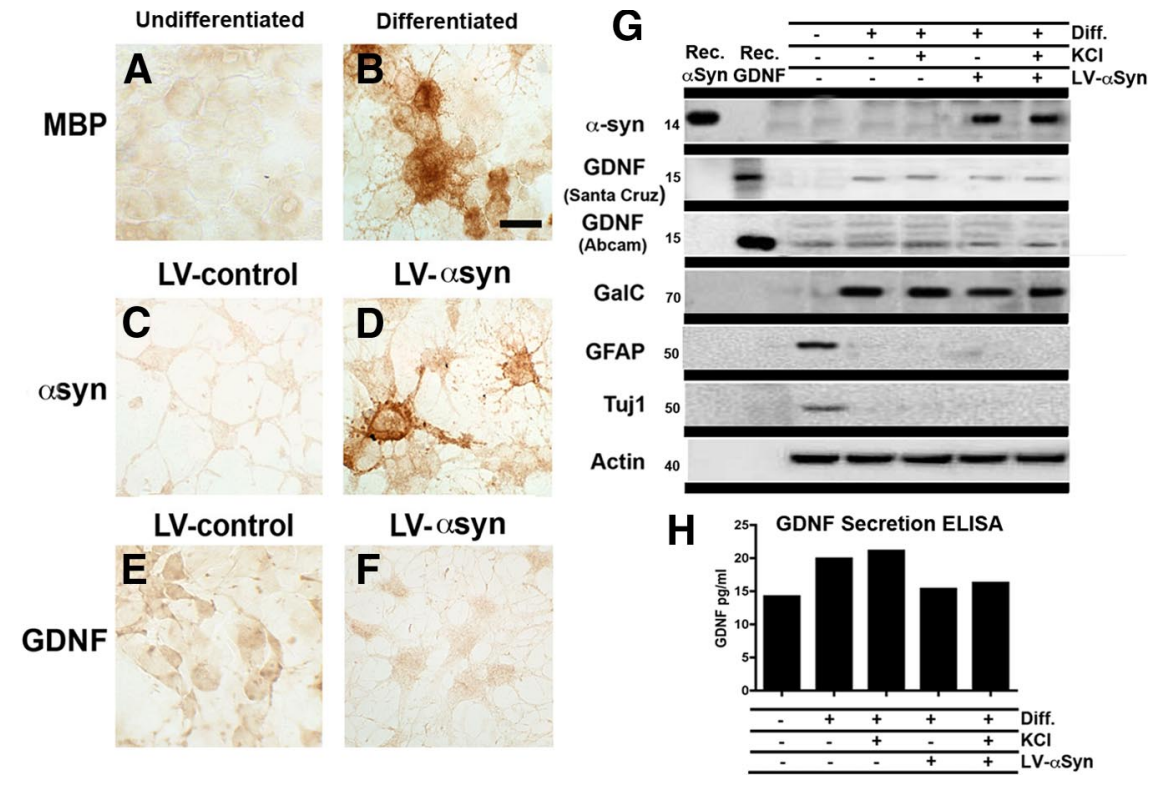

Figure 4. In vitro characterization of the effect of $\alpha$ syn on GDNF expression. To examine the in vitro effect of $\alpha$ syn on GDNF expression NPCs were differentiated to an oligodendrocytic phenotype, confirmed by MBP immunoreactivity $(\boldsymbol{A}, \boldsymbol{B})$. These cells were then infected with LV-control (C) or LV- $\alpha$ syn (D); infection was confirmed by $\alpha$ syn immunoreactivity. GDNF immunoreactivity was examined in the NPC-derived oligodendrocytes infected with LV-control vector $(\boldsymbol{E})$ or LV- $\alpha$ syn $(\boldsymbol{F})$. To complement immunocytochemical studies, immunoblot analysis was also conduced to confirm differentiation, LV- $\alpha$ syn expression, and the effect of $L V$ - $\alpha$ syn on levels of GDNF (G); conditioned media from these cells was used to determine levels of secreted GDNF by ELISA (H). KCl (55 mm) was used to enhance GDNF secretion as a positive control. Scale bar: $\boldsymbol{A}-\boldsymbol{F}, 20 \mu \mathrm{m}$.
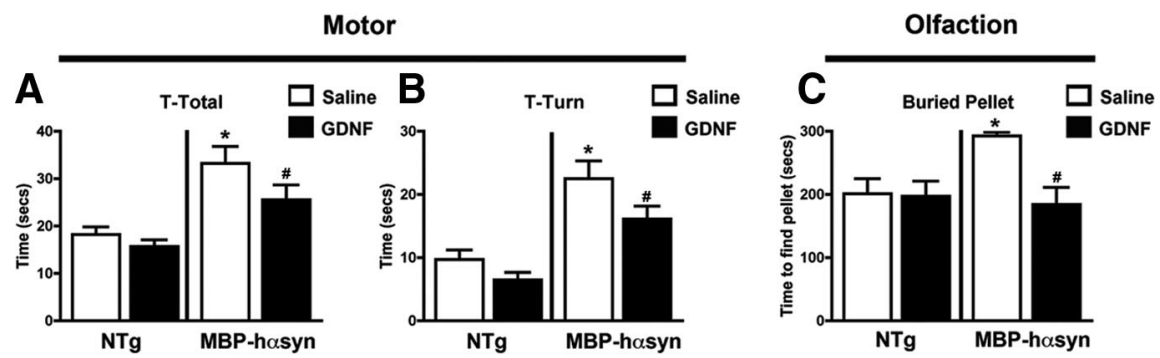

Figure 5. Behavioral deficits in MBP-h $\alpha$ syn Tg mice are attenuated by GDNF infusion. To assess the behavioral effects of GDNF infusion, motor behavior was assessed via the pole test; total time taken to descend the pole $(\boldsymbol{A})$ and time taken to face downward on the pole $(\boldsymbol{B})$ were recorded. Olfactory function was assessed using the buried pellet test, and time taken to find the pellet was recorded $(C)$ ( $n=6$; age, 8 months in each group). *Significant difference between saline-infused NTg and MBP-h $\alpha$ syn Tg mice $(p<0.05$, one-way ANOVA and post hoc Fisher). "Significant difference between saline-infused and GDNF-infused MBP-h $\alpha$ syn Tg mice ( $p<0.05$, one-way ANOVA and post hoc Fisher). Error bars indicate SEM.

infusion had no effect on the time taken by the NTg mice to find the pellet.

GDNF infusion ameliorates the neurodegenerative alterations in MBP-hasyn Tg mice

Immunohistochemical analysis was performed to assess the effects of GDNF infusion on neuropathology in the MBP-h $\alpha$ syn Tg mice. GDNF immunoreactivity was detected in the neocortex and white matter tracts of saline-infused NTg and MBP-h $\alpha$ syn $\mathrm{Tg}$ mice; the antibody also recognized cells with oligodendroglial and astroglial characteristics along the white matter tracts in the corpus callosum and striatum (Fig. 6A-D, insets at higher magnification). Consistent with immunoblot analysis, immunohistochemical studies showed a significant reduction in the levels of GDNF immunoreactivity in the saline-infused MBP-h $\alpha$ syn Tg mice compared with the saline-infused NTg control mice (Fig. 6A, $C$; analyzed in $E$ ). GDNF infusion significantly increased levels of GDNF immunoreactivity in both MBP-hosyn $\mathrm{Tg}$ and NTg mice (Fig. $6 B, D$; analyzed in $E$ ). Immunohistochemical analysis of GFAP showed no differences between saline- or GDNFinfused MBP-h $\alpha$ syn Tg mice and NTg mice (Fig. 6F-I; analyzed in J).

Immunohistochemical analysis of dendritic pathology, as evidenced by MAP-2 immunoreactivity, demonstrated a significant reduction of MAP-2-immunoreactive neuropil in the saline-infused MBP-h $\alpha$ syn Tg mice compared with the saline-infused NTg mice (Fig. 7A,C); GDNF infusion ameliorated the dendritic pathology as evidenced by MAP-2-immunoreactive neuropil in the MBP-h $\alpha$ syn Tg mice, bringing it into line with NTg levels (Fig. $7 A, C, D$; analyzed in $E$ ). GDNF infusion had no significant effect on the levels of MAP-2-immunoreactive neuropil in the NTg mice. Consistent with previous studies (Shults et al., 2005), the saline-infused MPBP-h $\alpha$ syn Tg mice displayed a significant reduction in the number of NeuN-immunoreactive neurons in the neocortex compared with saline-infused NTg (Fig. 7F,H), which was improved on GDNF infusion (Fig. $7 F, G$, I; analyzed in $J$ ). Together, these studies suggest that the reduced levels of GDNF observed in MBP-h $\alpha$ syn Tg mice, in concert with alterations in other NTFs, play a role in the neuropathological alterations present in these $\mathrm{Tg}$ mice and that GDNF infusion is able to alleviate the neuropathological and behavioral deficits observed in these $\mathrm{Tg}$ mice.

Analysis of TH immunoreactivity in the caudoputamen (Fig. 8A-D; analyzed in $E$ ) and substantia nigra (Fig. $8 A-I$; analyzed in $J$ ) demonstrated a significant decrease in TH-immunoreactive fibers and cells in these regions in the saline-infused MBP-h $\alpha$ syn mice compared with the saline-infused NTg mice. GDNF infusion increased TH immunoreactivity in fibers in the caudoputamen (Fig. $8 A, D$ ) and cells in the substantia nigra (Fig. 8A,I) in the MBP-h $\alpha$ syn Tg mice compared with salineinfused MBP-h $\alpha$ syn Tg mice. These effects of GDNF on TH immunoreactivity in regions involved with motor behavior are consistent with previous reports (Sun et al., 2004; Pascual et al., 2008) and with the pole test results presented here. Analysis of DAT immunoreactivity in the caudoputamen (Fig. $8 \mathrm{~K}-\mathrm{N}$; analyzed in $O$ ) demonstrated a significant decrease in DATimmunoreactive fibers in the saline-infused MBP-h $\alpha$ syn mice compared with the saline-infused NTg mice (Fig. $8 K, M$; analyzed in $O$ ), and GDNF infusion increased DAT immunoreactivity in fibers in the caudoputamen in the MBP-h $\alpha$ syn $\mathrm{Tg}$ mice compared with saline-infused MBP-h $\alpha$ syn Tg mice (Fig. 8M,N; analyzed in $O$ ).

\section{Effects of GDNF infusion on $\alpha$ syn levels}

To investigate the effects of GDNF infusion on protein levels of $\alpha$ syn, immunohistochemistry and immunoblot were conducted. 
NTg/Saline
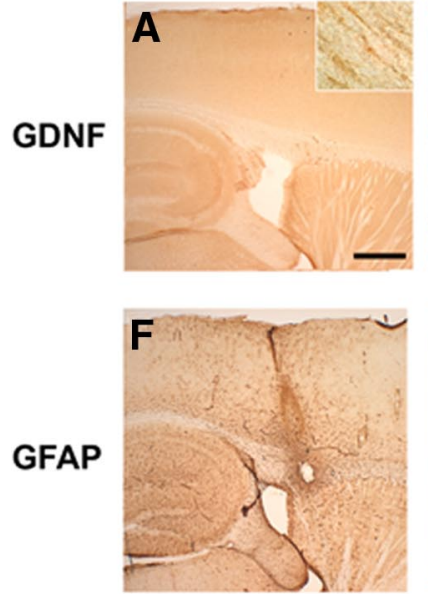

NTg/GDNF
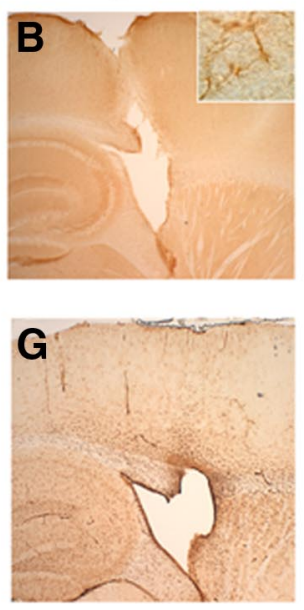

MBP-hosyn/Saline MBP-h $\alpha$ syn/GDNF
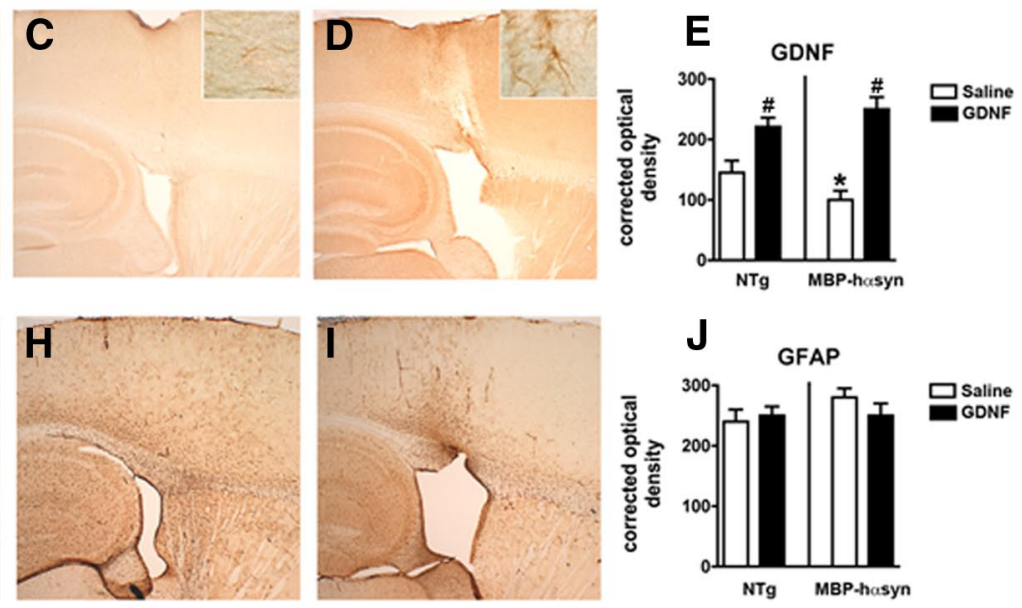

Figure 6. Immunohistochemical characterization of NTg and MBP-h $\alpha$ syn Tg mice after GDNF infusion. To assess the effect of GNDF infusion on neuropathology, immunohistochemical analysis of GDNF immunoreactivity in saline-infused NTg mice $(\boldsymbol{A})$, GDNF-infused NTg mice $(\boldsymbol{B})$, saline-infused MBP-h $\alpha$ syn Tg mice (C), and GDNF-infused MBP-h $\alpha$ syn Tg mice (D) was performed and analyzed in $\boldsymbol{E}(n=6$; age, 8 months in each group). GFAP immunoreactivity in saline-infused NTg mice $(\boldsymbol{F})$, GDNF-infused NTg mice ( $\boldsymbol{G}$ ), saline-infused MBP-h $\alpha$ syn Tg mice $(\boldsymbol{H})$, and GDNF-infused MBP-h $\alpha$ syn $\mathrm{Tg}$ mice $(\boldsymbol{I})$ was also measured and analyzed in $\boldsymbol{J}\left(\boldsymbol{n}=6\right.$; age, 8 months in each group). Scale bar, $200 \mu \mathrm{m}$ (insets at higher magnification). ${ }^{*}$ Significant difference between saline-infused NTg and MBP-h $\alpha$ syn Tg mice ( $p<0.05$, one-way ANOVA and post hoc Fisher). "Significant difference between saline-infused and GDNF-infused NTg or MBP-h $\alpha$ syn Tg mice ( $p<$ 0.05 , one-way ANOVA and post hoc Fisher). Error bars indicate SEM.
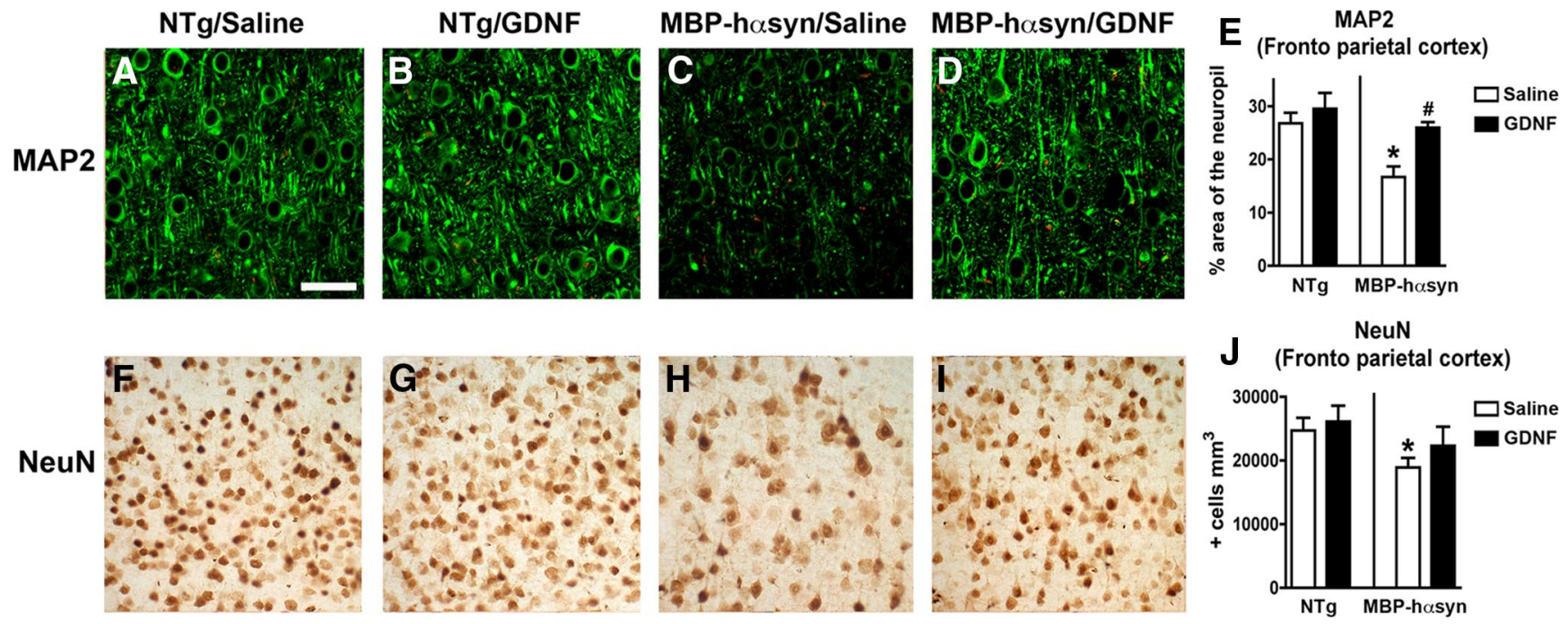

Figure 7. Immunohistochemical characterization of dendritic pathology and neuronal density in NTg and MBP-h $\alpha$ syn Tg mice after GDNF infusion. Dendritic pathology was assessed via MAP-2 immunoreactivity in the frontoparietal cortex of saline-infused NTg mice (A), GDNF-infused NTg mice $(\boldsymbol{B})$, saline-infused MBP-h $\alpha$ syn Tg mice $(\boldsymbol{C}$ ), and GDNF-infused MBP-h $\alpha$ syn Tg mice (D), and analyzed in $\boldsymbol{E}(n=6$; age, 8 months in each group). Neurodegeneration was assessed via NeuN immunoreactivity in the frontoparietal cortex of saline-infused NTg mice $(\boldsymbol{F})$, GDNF-infused NTg mice $(\boldsymbol{G})$, saline-infused MBP-h $\alpha$ syn Tg mice $(\boldsymbol{H})$, and GDNF-infused MBP-h $\alpha$ syn Tg mice $(\boldsymbol{I})$, and analyzed in $\boldsymbol{J}\left(n=6\right.$; age, 8 months in each group). Scale bar, $30 \mu \mathrm{m}$. ${ }^{*}$ Significant difference between saline-infused NTg and MBP-h $\alpha$ syn Tg mice ( $p<0.05$, one-way ANOVA and post hoc Fisher). "Significant difference between saline-infused and GDNF-infused MBP-h $\alpha$ syn Tg mice ( $p<0.05$, one-way ANOVA and post hoc Fisher). Error bars indicate SEM.

Consistent with previous reports (Shults et al., 2005; Ubhi et al., 2009), immunohistochemical analysis demonstrated abundant $\alpha$ syn-immunoreactive oligodendrocytes in the saline-infused MBPhosyn Tg mice compared with saline-infused NTg mice (Fig. $9 A, E, C, G$; analyzed in $I$ ). GDNF infusion had no effect on $\alpha$-syn levels in the MBP-h $\alpha$ syn Tg or NTg mice (Fig. 9B, F,D, H; analyzed in $I$ ).

Immunoblot analysis of the MBP-h $\alpha$ syn Tg mice showed a significant increase in phosphorylated (supplemental Fig. $2 \mathrm{~A}, \mathrm{C}$, available at www.jneurosci.org as supplemental material) and total (supplemental Fig. 2A,D, available at www.jneurosci.org as supplemental material) $\alpha$ syn levels in the saline-infused MBPh $\alpha$ syn Tg mice compared with saline-infused NTg mice, and, consistent with the immunohistochemistry, immunoblot analy- sis showed no effect of GDNF infusion on levels of phosphorylated or total $\alpha$ syn in either the MBP-h $\alpha$ syn Tg or NTg mice. These results indicate that the beneficial effects of GDNF infusion on motor and olfactory behavior and on TH cell survival occur in an $\alpha$ syn-independent manner.

GDNF levels are altered in human MSA brains

Having established a reduction in GDNF levels in the MBPh $\alpha$ syn mice, we were interested in investigating whether a similar deficit was apparent in human MSA samples. To examine GDNF levels in humans, immunoblot and ELISA analysis was conducted (Fig. 10) on samples from the white matter of the frontal cortex and cerebellum in human patients, key areas implicated in 

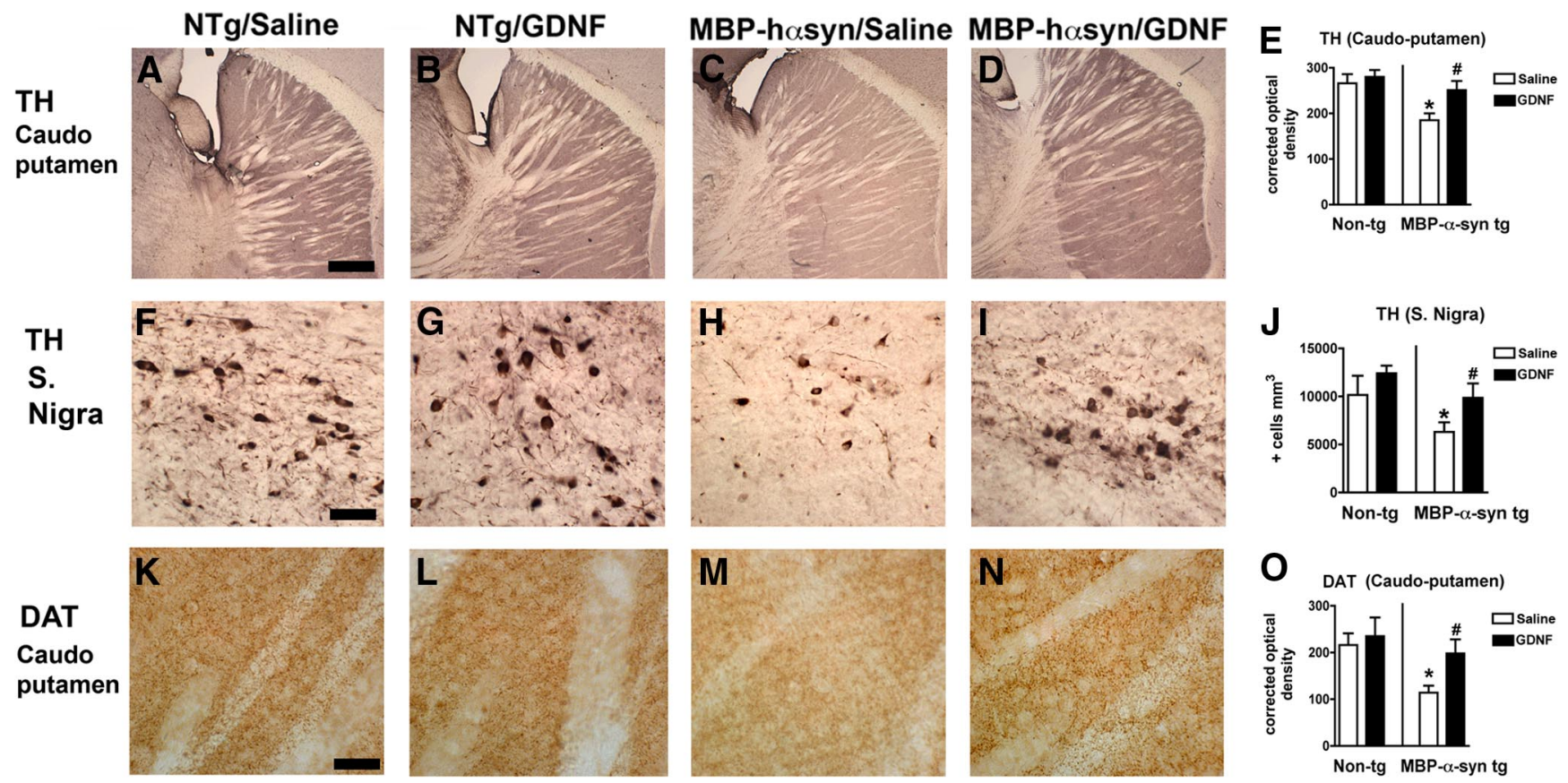

Figure 8. Dopamine marker immunoreactivity in motor regions of MBP-hsyn Tg mice after GDNF infusion. To examine the effects of GDNF infusion on dopaminergic cells, TH immunoreactivity in the caudoputamen of saline-infused NTg mice $(\boldsymbol{A})$, GDNF-infused NTg mice (B), saline-infused MBP-hsyn Tg mice $(\boldsymbol{C})$, and GDNF-infused MBP-hsyn Tg mice (D) was measured and analyzed in $\boldsymbol{E}(n=6$; age, 8 months in each group). TH immunoreactivity was also measured in the substantia nigra of saline-infused NTg mice $(\boldsymbol{F})$, GDNF-infused NTg mice $(\boldsymbol{G})$, saline-infused MBP-hsyn Tg mice $(\boldsymbol{H})$, and GDNF-infused MBP-hsyn Tg mice $(\boldsymbol{I})$, and analyzed in $\boldsymbol{J}(n=6$; age, 8 months in each group). Levels of DAT were also measured by immunohistochemistry in the caudoputamen of saline-infused NTg mice $(\boldsymbol{K})$, GDNF-infused NTg mice $(\boldsymbol{L})$, saline-infused MBP-hsyn Tg mice $(\boldsymbol{M})$, and GDNF-infused MBP-hsyn Tg mice $(\boldsymbol{N})$, and measured and analyzed in $\mathbf{O}\left(n=6\right.$; age, 8 months in each group). Scale bars: $\boldsymbol{A}-\boldsymbol{D}, \boldsymbol{K}-\boldsymbol{N}, 200 \mu \mathrm{m} ; \boldsymbol{F}-\mathbf{I}, 50 \mu \mathrm{m}$. ${ }^{*}$ Significant difference between saline-treated MBP-hsyn Tg mice and NTg ( $p<0.05$, one-way ANOVA and post hoc Fisher). "Significant difference between saline-treated MBP-hsyn Tg mice and GDNF-treated MBP-hsyn ( $p<0.05$, one-way ANOVA and post hoc Fisher). Error bars indicate SEM.

MSA pathology (Armstrong et al., 2007; Brenneis et al., 2007; Chang et al., 2009). Immunoblot analysis demonstrated a significant decrease of $50 \%$ in the levels of GDNF in the white matter of the frontal cortex of the MSA patients compared with the controls (Fig. 10A; quantified in $B$ ); in the cerebellum, however, although there was a greater variability in the expression of GDNF, the overall trend also seems to suggest reduced levels in the MSA patients compared with controls (Fig. 10A; quantified in $B$ ). GDNF levels measured by ELISA were consisted with the immunoblot results (Fig. 10C).

\section{Discussion}

The present study sought to investigate the hypothesis that oligodendrocytic accumulation of $\alpha$ syn, as observed in MSA, may disrupt expression of oligodendrocyte-derived NTFs. Our results demonstrate that, whereas levels of BDNF and IGF-1 were disrupted in Tg mice overexpressing $\alpha$ syn under both neuronal and oligodendrocytic promoters, only GDNF was specifically reduced in the MBPh $\alpha$ syn mice that accumulate $\alpha$ syn in oligodendrocytes. This finding was corroborated in vitro with oligodendrocytes derived from NPCs and infected with LV- $\alpha$ syn. The use of $\mathrm{KCl}$ as an inducer of GNDF secretion in the NPC-derived oligodendrocytes provided important information as to the impact of the GDNF deficit in LV- $\alpha$ syninfected cells. Although the uninfected cells were able to increase GDNF secretion on $\mathrm{KCl}$ administration, indicating the presence of a GDNF reserve, the LV- $\alpha$ syn-infected cells were unable to do so; this suggests that LV- $\alpha$ syn expression not only reduces the expression level of GDNF but also interferes with the secretion of GDNF by these cells.

Consistent with the results from the MBP-h $\alpha$ syn Tg mice and the NPC-derived oligodendrocytes, examination of GDNF levels in human MSA patients also demonstrated a reduction in GDNF levels, indicating that GDNF may also play an important role in MSA in humans.

Collectively, these results point toward the possibility that oligodendrocytic accumulation of $\alpha$ syn in MSA may interfere with the expression of NTFs and disrupt the neurotrophic support provided by the oligodendrocytes to the neurons, resulting in altered neuronal function and survival.

Several NTFs, such as NGF, BDNF, and GDNF itself, have been widely reported to be altered in a number of neurodegenerative disorders (Siegel and Chauhan, 2000; Capsoni and Cattaneo, 2006; Zuccato and Cattaneo, 2009), and many studies have looked at NTF replacement strategies in an effort to stave of neuronal dysfunction and death in these disorders with a number reporting beneficial effects (Lad et al., 2003; Peterson and Nutt, 2008; Ramaswamy et al., 2009; Sadan et al., 2009; Saragovi et al., 2009). Although we report alterations in a number of NTFs in the MBP-h $\alpha$ syn Tg mice, we chose to focus on GDNF as its role in MSA remains elusive, unlike BDNF (Kawamoto et al., 1999; Nishimura et al., 2005) and bFGF2 (Sarchielli et al., 2008), which have been reported to be altered in MSA. We were also interested in GDNF in relation to its role in olfactory function, an early deficit in MSA and other $\alpha$-synucleinopathies (Abele et al., 2003) and its reported ability to restore motor function (Gill et al., 2003; Slevin et al., 2005). Although we chose to focus on GDNF, we appreciate that augmentation of levels of the other NTFs may also have had an equally beneficial effect.

In addition to its expression by oligodendrocytes ( $\mathrm{Du}$ and Dreyfus, 2002; Wilkins et al., 2003), GDNF has also been reported in cortical neurons (Schaar et al., 1993; Choi-Lundberg and 


\section{NTg/Saline}
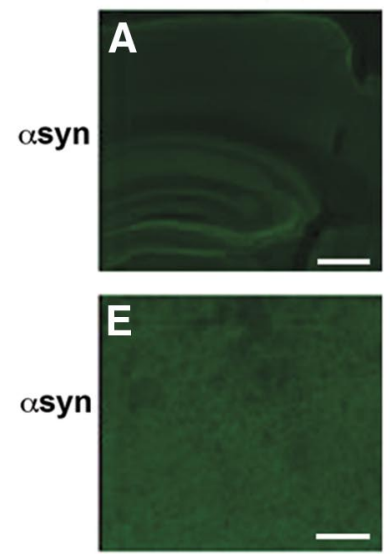

NTg/GDNF
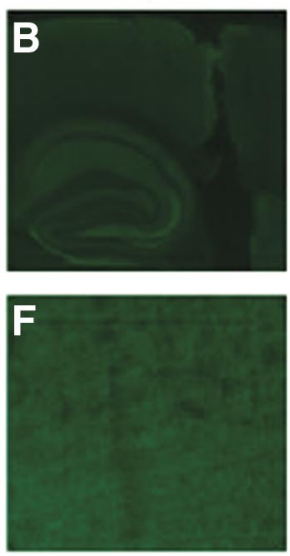

MBP-h $\alpha$ syn/Saline
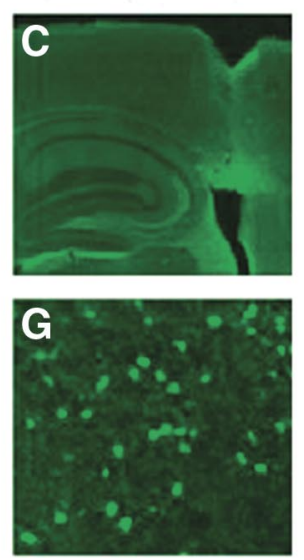

\section{MBP-h $\alpha$ syn/GDNF}

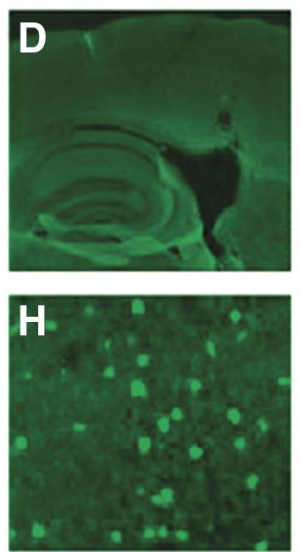

I $\alpha$-synuclein

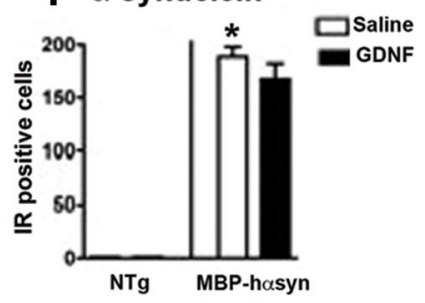

Figure 9. Immunohistochemical characterization of $\alpha$ syn expression in NTg and MBP-h $\alpha$ syn Tg mice after GDNF infusion. To determine the effect of GDNF infusion on $\alpha$ syn levels, $\alpha$ syn immunoreactivity in the cortex of saline-infused NTg mice $(\boldsymbol{A}, \boldsymbol{E})$, GDNF-infused NTg mice $(\boldsymbol{B}, \boldsymbol{F})$, saline-infused MBP-h $\alpha$ syn Tg mice $(\boldsymbol{C}, \boldsymbol{G})$, and GDNF-infused MBP-h $\alpha$ syn Tg mice $(\boldsymbol{D}, \boldsymbol{H})$ was measured and analyzed in I. Scale bars: $\boldsymbol{A}-\boldsymbol{D}, 200 \mu \mathrm{m} ; \boldsymbol{E}-\boldsymbol{H}, 50 \mu \mathrm{m}$. *Significant difference between saline-infused NTg and MBP-h $\alpha$ syn Tg mice ( $p<0.05$, one-way AN0VA and post hoc Fisher). Error bars indicate SEM.

Bohn, 1995; Pochon et al., 1997) and astrocytes (Ho et al., 1995); it therefore could be argued that the loss of GDNF seen in the MBP-h $\alpha$ syn Tg mice may represent a loss from one of these other sources; however, given the lack of cortical astrogliosis, which would indicate the loss of surrounding cortical neurons (and hence a possible loss of neuronally derived GDNF) and the lack of a reduction in GFAP immunoreactivity in the MBPhosyn Tg mice, which would indicate reduction in astrocyte number (and hence astrocyte-derived GDNF), the most parsimonious explanation is that the loss of GDNF observed in these mice is indeed that of oligodendrocytic origin. We also demonstrate that the expression of GDNF is reduced at a protein level, with GDNF mRNA as assessed by ISH and qRT-PCR showing no differences between MBP-h $\alpha$ syn Tg mice and NTg mice. This would indicate that the effects of $\alpha$ syn on GDNF are posttranscriptional, perhaps involving the stability or degradation of GDNF; these effects are potentially very interesting and merit additional characterization. This loss is specific to GDNF, with other family members being unaltered in the MBP-h $\alpha$ syn Tg mice, whereas analysis of GFR demonstrated a specific alteration only in levels of GFR $\alpha 1$, the GDNF-specific receptor.

In an effort to assess the pathological importance of the GDNF deficit, an infusion of GDNF was performed and the mice were assessed behaviorally and biochemically. The MBP-h $\alpha$ syn Tg mice have been extensively characterized and shown to display motor behavioral deficits as assessed by the pole test (Shults et al., 2005; Ubhi et al., 2009), a test of basal ganglia function (Matsuura et al., 1997). The results here demonstrate an attenuation of the motor deficits in the MBP-h $\alpha$ syn Tg mice on GDNF infusion; these results were consistent with the increase in caudoputamen and substantia nigra $\mathrm{TH}$ immunoreactivity observed in the GDNF-infused MBP-h $\alpha$ syn Tg mice compared with salineinfused MBP-h $\alpha$ syn Tg mice and with previous reports of the effects of GDNF on TH-positive cells (Boger et al., 2006; Emborg et al., 2008; He and Ron, 2008; Pascual et al., 2008) and a previous study showing behavioral improvement in a mouse model of MSA that had been treated with rasagiline (Stefanova et al., 2008). Although rasagiline, a drug used in the treatment of $\mathrm{PD}$, has been reported to act via GDNF and BDNF induction (Stefanova et al., 2008), this study is the first to report a behavioral attenuation in a Tg model of MSA that can be directly attributed to an increased expression of GDNF.

Additional behavioral deficits, specifically of olfactory function, were assessed via the buried pellet test. Here again, GDNF infusion attenuated the behavioral deficit by significantly reducing the time taken by the MBP-h $\alpha$ syn Tg mice to locate the buried food pellet compared with saline-infused MBP-h $\alpha$ syn Tg mice. These results are important for a number of reasons; first, this study is the first to demonstrate the olfactory deficit in the MBPh $\alpha$ syn Tg mice, and second, olfactory dysfunction is widely reported by sufferers of a number of $\alpha$-synucleinopathies including MSA (Nee et al., 1993; Abele et al., 2003; Hawkes, 2006); additionally, MSA patients have GCIs in their olfactory bulbs and neuronal loss in the anterior olfactory nucleus (Kovács et al., 2003). These results are consistent with studies reporting the ability of GDNF to promote the migration of olfactory ensheathing cells, glial cells that ensheath the olfactory nerves (Cao et al., 2006). Additional investigation of the expression of GDNF in the olfactory bulbs of the MBP- $\alpha$ syn and the role it may play in the observed olfactory deficit is necessary to fully understand the mechanisms that may underlie this symptom.

GDNF has been extensively investigated in relation to PD (Barker, 2006; Chen et al., 2008; Emborg et al., 2008; Hong et al., 2008). Initially purified in 1993 as a growth factor promoting embryonic midbrain dopaminergic neuron survival (Lin et al., 
1993, 1994), it has since been shown to being necessary for the survival of adult catecholaminergic neurons (Pascual et al., 2008) as well as a trophic factor for spinal motorneurones (Henderson et al., 1994) and central noradrenergic neurons (Arenas et al., 1995). Although the mechanisms through which $\alpha$ syn expression alters GDNF levels remain unclear, the results from this study demonstrate no alteration of GDNF mRNA levels in the MBPh $\alpha$ syn Tg mice compared with the NTg mice, suggesting that whatever effect $\alpha$ syn is having, it is posttranscriptionally located. The apparent upregulation of the GFR $\alpha 1$ receptor subunit in the MBP-h $\alpha$ syn mice is also interesting as it suggests a potential compensatory mechanism in these mice. Additional characterization of the GDNF signaling pathway, secretion mechanisms, and interconnected pathways is a key area of future investigation.

Despite the well known role of GDNF in PD (Barker, 2006; Patel and Gill, 2007; Yasuhara et al., 2007; Hong et al., 2008), the role of this NTF in MSA has remained unclear; collectively, the results from this study suggest a pathway of communication between oligodendrocytes and neurons, involving the production of NTFs, which may become perturbed on oligodendrocytic $\alpha$ syn accumulation as observed in MSA and suggest that GDNF, in combination with other NTFs such as BDNF, may have a wider therapeutic relevance than previously supposed.

\section{References}

Abele M, Riet A, Hummel T, Klockgether T, Wüllner U (2003) Olfactory dysfunction in cerebellar ataxia and multiple system atrophy. J Neurol 250:1453-1455.

Aleman A, Torres-Alemán I (2009) Circulating insulin-like growth factor I and cognitive function: neuromodulation throughout the lifespan. Prog Neurobiol 89:256-265.

Arenas E, Trupp M, Akerud P, Ibáñez CF (1995) GDNF prevents degeneration and promotes the phenotype of brain noradrenergic neurons in vivo. Neuron 15:1465-1473.

Arima K, Uéda K, Sunohara N, Arakawa K, Hirai S, Nakamura M, TonozukaUehara H, Kawai M (1998) NACP/alpha-synuclein immunoreactivity in fibrillary components of neuronal and oligodendroglial cytoplasmic inclusions in the pontine nuclei in multiple system atrophy. Acta Neuropathol 96:439-444.

Armstrong RA, Cairns NJ, Lantos PL (2007) A quantitative study of the pathological changes in white matter in multiple system atrophy. Neuropathology 27:221-227.

Barker RA (2006) Continuing trials of GDNF in Parkinson's disease. Lancet Neurol 5:285-286.

Blin O, Desnuelle C, Rascol O, Borg M, Peyro Saint Paul H, Azulay JP, Billé F, Figarella D, Coulom F, Pellissier JF (1994) Mitochondrial respiratory failure in skeletal muscle from patients with Parkinson's disease and multiple system atrophy. J Neurol Sci 125:95-101.

Boger HA, Middaugh LD, Huang P, Zaman V, Smith AC, Hoffer BJ, Tomac AC, Granholm AC (2006) A partial GDNF depletion leads to earlier age-related deterioration of motor function and tyrosine hydroxylase expression in the substantia nigra. Exp Neurol 202:336-347.

Brenneis C, Egger K, Scherfler C, Seppi K, Schocke M, Poewe W, Wenning GK (2007) Progression of brain atrophy in multiple system atrophy. A longitudinal VBM study. J Neurol 254:191-196.

Cao L, Su Z, Zhou Q, Lv B, Liu X, Jiao L, Li Z, Zhu Y, Huang Z, Huang A, He C (2006) Glial cell line-derived neurotrophic factor promotes olfactory ensheathing cells migration. Glia 54:536-544.

Capsoni S, Cattaneo A (2006) On the molecular basis linking nerve growth factor (NGF) to Alzheimer's disease. Cell Mol Neurobiol 26:619-633.

Chang CC, Chang YY, Chang WN, Lee YC, Wang YL, Lui CC, Huang CW, Liu WL (2009) Cognitive deficits in multiple system atrophy correlate with frontal atrophy and disease duration. Eur J Neurol 16:1144-1150.

Chen YH, Harvey BK, Hoffman AF, Wang Y, Chiang YH, Lupica CR (2008) MPTP-induced deficits in striatal synaptic plasticity are prevented by glial cell line-derived neurotrophic factor expressed via an adeno-associated viral vector. FASEB J 22:261-275.

Choi-Lundberg DL, Bohn MC (1995) Ontogeny and distribution of glial cell line-derived neurotrophic factor (GDNF) mRNA in rat. Brain Res Dev Brain Res 85:80-88.

Dai X, Qu P, Dreyfus CF (2001) Neuronal signals regulate neurotrophin expression in oligodendrocytes of the basal forebrain. Glia 34:234-239.

Dai X, Lercher LD, Clinton PM, Du Y, Livingston DL, Vieira C, Yang L, Shen MM, Dreyfus CF (2003) The trophic role of oligodendrocytes in the basal forebrain. J Neurosci 23:5846-5853.

Du Y, Dreyfus CF (2002) Oligodendrocytes as providers of growth factors. J Neurosci Res 68:647-654.

Emborg ME, Ebert AD, Moirano J, Peng S, Suzuki M, Capowski E, Joers V, Roitberg BZ, Aebischer P, Svendsen CN (2008) GDNF-secreting human neural progenitor cells increase tyrosine hydroxylase and VMAT2 expression in MPTP-treated cynomolgus monkeys. Cell Transplant 17:383-395.

Ferrara N, Ousley F, Gospodarowicz D (1988) Bovine brain astrocytes express basic fibroblast growth factor, a neurotropic and angiogenic mitogen. Brain Res 462:223-232.

Fujiwara H, Hasegawa M, Dohmae N, Kawashima A, Masliah E, Goldberg MS, Shen J, Takio K, Iwatsubo T (2002) alpha-Synuclein is phosphorylated in synucleinopathy lesions. Nat Cell Biol 4:160-164.

Gill SS, Patel NK, Hotton GR, O'Sullivan K, McCarter R, Bunnage M, Brooks DJ, Svendsen CN, Heywood P (2003) Direct brain infusion of glial cell line-derived neurotrophic factor in Parkinson disease. Nat Med 9:589-595.

Hawkes C (2006) Olfaction in neurodegenerative disorder. Adv Otorhinolaryngol 63:133-151.

Hayashi M, Mistunaga F, Ohira K, Shimizu K (2001) Changes in BDNFimmunoreactive structures in the hippocampal formation of the aged macaque monkey. Brain Res 918:191-196.

He DY, Ron D (2008) Glial cell line-derived neurotrophic factor reverses ethanol-mediated increases in tyrosine hydroxylase immunoreactivity via altering the activity of heat shock protein 90. J Biol Chem 283:12811-12818.

Henderson CE, Phillips HS, Pollock RA, Davies AM, Lemeulle C, Armanini M, Simmons L, Moffet B, Vandlen RA, Simmons L (1994) GDNF: a potent survival factor for motoneurons present in peripheral nerve and muscle. Science 266:1062-1064.

Ho A, Gore AC, Weickert CS, Blum M (1995) Glutamate regulation of GDNF gene expression in the striatum and primary striatal astrocytes. Neuroreport 6:1454-1458.

Hong M, Mukhida K, Mendez I (2008) GDNF therapy for Parkinson's disease. Expert Rev Neurother 8:1125-1139.

Hsieh J, Aimone JB, Kaspar BK, Kuwabara T, Nakashima K, Gage FH (2004) IGF-I instructs multipotent adult neural progenitor cells to become oligodendrocytes. J Cell Biol 164:111-122.

Iranmanesh A, Lizarralde G, Veldhuis JD (1991) Age and relative adiposity are specific negative determinants of the frequency and amplitude of growth hormone $(\mathrm{GH})$ secretory bursts and the half-life of endogenous GH in healthy men. J Clin Endocrinol Metab 73:1081-1088.

Kawamoto Y, Nakamura S, Akiguchi I, Kimura J (1999) Increased brainderived neurotrophic factor-containing axons in the basal ganglia of patients with multiple system atrophy. J Neuropathol Exp Neurol 58:765-772.

Kovács T, Papp MI, Cairns NJ, Khan MN, Lantos PL (2003) Olfactory bulb in multiple system atrophy. Mov Disord 18:938-942.

Lad SP, Neet KE, Mufson EJ (2003) Nerve growth factor: structure, function and therapeutic implications for Alzheimer's disease. Curr Drug Targets CNS Neurol Disord 2:315-334.

Lin LF, Doherty DH, Lile JD, Bektesh S, Collins F (1993) GDNF: a glial cell line-derived neurotrophic factor for midbrain dopaminergic neurons. Science 260:1130-1132.

Lin LF, Zhang TJ, Collins F, Armes LG (1994) Purification and initial characterization of rat B49 glial cell line-derived neurotrophic factor. J Neurochem 63:758-768.

Matsuura K, Kabuto H, Makino H, Ogawa N (1997) Pole test is a useful method for evaluating the mouse movement disorder caused by striatal dopamine depletion. J Neurosci Methods 73:45-48.

Mattson MP, Maudsley S, Martin B (2004) A neural signaling triumvirate that influences ageing and age-related disease: insulin/IGF-1, BDNF and serotonin. Ageing Res Rev 3:445-464.

Nee LE, Scott J, Polinsky RJ (1993) Olfactory dysfunction in the Shy-Drager syndrome. Clin Auton Res 3:281-282.

Nishimura M, Kuno S, Kaji R, Kawakami H (2005) Brain-derived neurotrophic factor gene polymorphisms in Japanese patients with sporadic Alz- 
heimer's disease, Parkinson's disease, and multiple system atrophy. Mov Disord 20:1031-1033.

Nosrat CA, Tomac A, Lindqvist E, Lindskog S, Humpel C, Strömberg I, Ebendal T, Hoffer BJ, Olson L (1996) Cellular expression of GDNF mRNA suggests multiple functions inside and outside the nervous system. Cell Tissue Res 286:191-207.

Oh-hashi K, Ito M, Tanaka T, Hirata Y, Kiuchi K (2009) Biosynthesis, processing, and secretion of glial cell line-derived neurotrophic factor in astroglial cells. Mol Cell Biochem 323:1-7.

Pascual A, Hidalgo-Figueroa M, Piruat JI, Pintado CO, Gómez-Díaz R, López-Barneo J (2008) Absolute requirement of GDNF for adult catecholaminergic neuron survival. Nat Neurosci 11:755-761.

Patel NK, Gill SS (2007) GDNF delivery for Parkinson's disease. Acta Neurochir Suppl 97:135-154.

Peterson AL, Nutt JG (2008) Treatment of Parkinson's disease with trophic factors. Neurotherapeutics 5:270-280.

Pochon NA, Menoud A, Tseng JL, Zurn AD, Aebischer P (1997) Neuronal GDNF expression in the adult rat nervous system identified by in situ hybridization. Eur J Neurosci 9:463-471.

Probst-Cousin S, Rickert CH, Schmid KW, Gullotta F (1998) Cell death mechanisms in multiple system atrophy. J Neuropathol Exp Neurol $57: 814-821$.

Ramaswamy S, Soderstrom KE, Kordower JH (2009) Trophic factors therapy in Parkinson's disease. Prog Brain Res 175:201-216.

Ray J, Gage FH (2006) Differential properties of adult rat and mouse brainderived neural stem/progenitor cells. Mol Cell Neurosci 31:560-573.

Rockenstein EM, McConlogue L, Tan H, Power M, Masliah E, Mucke L (1995) Levels and alternative splicing of amyloid beta protein precursor (APP) transcripts in brains of APP transgenic mice and humans with Alzheimer's disease. J Biol Chem 270:28257-28267.

Rockenstein E, Mallory M, Hashimoto M, Song D, Shults CW, Lang I, Masliah E (2002) Differential neuropathological alterations in transgenic mice expressing alpha-synuclein from the platelet-derived growth factor and Thy-1 promoters. J Neurosci Res 68:568-578.

Rose JB, Crews L, Rockenstein E, Adame A, Mante M, Hersh LB, Gage FH, Spencer B, Potkar R, Marr RA, Masliah E (2009) Neuropeptide Y fragments derived from neprilysin processing are neuroprotective in a transgenic model of Alzheimer's disease. J Neurosci 29:1115-1125.

Rudman D, Kutner MH, Rogers CM, Lubin MF, Fleming GA, Bain RP (1981) Impaired growth hormone secretion in the adult population: relation to age and adiposity. J Clin Invest 67:1361-1369.

Sadan O, Bahat-Stromza M, Barhum Y, Levy YS, Pisnevsky A, Peretz H, Ilan AB, Bulvik S, Shemesh N, Krepel D, Cohen Y, Melamed E, Offen D (2009) Protective effects of neurotrophic factor-secreting cells in a 6-OHDA rat model of Parkinson disease. Stem Cells Dev 18:1179-1190.

Saragovi HU, Hamel E, Di Polo A (2009) A neurotrophic rationale for the therapy of neurodegenerative disorders. Curr Alzheimer Res 6:419-423.

Sarchielli P, Di Filippo M, Ercolani MV, Chiasserini D, Mattioni A, Bonucci M, Tenaglia S, Eusebi P, Calabresi P (2008) Fibroblast growth factor-2 levels are elevated in the cerebrospinal fluid of multiple sclerosis patients. Neurosci Lett 435:223-228.

Schaar DG, Sieber BA, Dreyfus CF, Black IB (1993) Regional and cellspecific expression of GDNF in rat brain. Exp Neurol 124:368-371.

Schulz JB, Beal MF (1994) Mitochondrial dysfunction in movement disorders. Curr Opin Neurol 7:333-339.
Shibasaki T, Shizume K, Nakahara M, Masuda A, Jibiki K, Demura H, Wakabayashi I, Ling N (1984) Age-related changes in plasma growth hormone response to growth hormone-releasing factor in man. J Clin Endocrinol Metab 58:212-214.

Shults CW, Rockenstein E, Crews L, Adame A, Mante M, Larrea G, Hashimoto M, Song D, Iwatsubo T, Tsuboi K, Masliah E (2005) Neurological and neurodegenerative alterations in a transgenic mouse model expressing human $\alpha$-synuclein under oligodendrocyte promoter: implications for multiple system atrophy. J Neurosci 25:10689-10699.

Siegel GJ, Chauhan NB (2000) Neurotrophic factors in Alzheimer's and Parkinson's disease brain. Brain Res Brain Res Rev 33:199-227.

Slevin JT, Gerhardt GA, Smith CD, Gash DM, Kryscio R, Young B (2005) Improvement of bilateral motor functions in patients with Parkinson disease through the unilateral intraputaminal infusion of glial cell linederived neurotrophic factor. J Neurosurg 102:216-222.

Stefanova N, Poewe W, Wenning GK (2008) Rasagiline is neuroprotective in a transgenic model of multiple system atrophy. Exp Neurol 210:421-427.

Sun ZH, Lai YL, Li P, Zuo HC, Xie ZP (2004) GDNF augments survival and differentiation of TH-positive neurons in neural progenitor cells. Cell Biol Int 28:323-325.

Tapia-Arancibia L, Aliaga E, Silhol M, Arancibia S (2008) New insights into brain BDNF function in normal aging and Alzheimer disease. Brain Res Rev 59:201-220.

Tu PH, Galvin JE, Baba M, Giasson B, Tomita T, Leight S, Nakajo S, Iwatsubo T, Trojanowski JQ, Lee VM (1998) Glial cytoplasmic inclusions in white matter oligodendrocytes of multiple system atrophy brains contain insoluble alpha-synuclein. Ann Neurol 44:415-422.

Ubhi K, Lee PH, Adame A, Inglis C, Mante M, Rockenstein E, Stefanova N, Wenning GK, Masliah E (2009) Mitochondrial inhibitor 3-nitroproprionic acid enhances oxidative modification of alpha-synuclein in a transgenic mouse model of multiple system atrophy. J Neurosci Res 87:2728-2739.

Wakabayashi K, Takahashi H (2006) Cellular pathology in multiple system atrophy. Neuropathology 26:338-345.

Wakabayashi K, Yoshimoto M, Tsuji S, Takahashi H (1998a) Alphasynuclein immunoreactivity in glial cytoplasmic inclusions in multiple system atrophy. Neurosci Lett 249:180-182.

Wakabayashi K, Hayashi S, Kakita A, Yamada M, Toyoshima Y, Yoshimoto M, Takahashi H (1998b) Accumulation of alpha-synuclein/NACP is a cytopathological feature common to Lewy body disease and multiple system atrophy. Acta Neuropathol 96:445-452.

Wilkins A, Chandran S, Compston A (2001) A role for oligodendrocytederived IGF-1 in trophic support of cortical neurons. Glia 36:48-57.

Wilkins A, Majed H, Layfield R, Compston A, Chandran S (2003) Oligodendrocytes promote neuronal survival and axonal length by distinct intracellular mechanisms: a novel role for oligodendrocyte-derived glial cell line-derived neurotrophic factor. J Neurosci 23:4967-4974.

Yasuhara T, Shingo T, Date I (2007) Glial cell line-derived neurotrophic factor (GDNF) therapy for Parkinson's disease. Acta Med Okayama 61:51-56.

Yoshida M (2007) Multiple system atrophy: alpha-synuclein and neuronal degeneration. Neuropathology 27:484-493.

Zuccato C, Cattaneo E (2009) Brain-derived neurotrophic factor in neurodegenerative diseases. Nat Rev Neurol 5:311-322. 